\title{
Do manufacturing firms need informality in ERP post-implementation? A study of Chinese manufacturing sites
}

Yucan Wang, Andrew Greasley and Pavel Albores

\section{Introduction}

Many organisations have achieved benefits from enterprise resource planning (ERP) systems, including improvements in efficiency by reducing process cycle time, producing documentation quickly, eliminating errors and removing duplicated processes (Moon and Phatak, 2005). However, there is an increasing awareness of the shortcomings of ERP systems because many companies are confronted by risks at the post-implementation stage when using, maintaining and enhancing their systems. This has led to an emphasis on the critical role of making ongoing improvements of systems by frontline employees in the ERP post-implementation stage (Gallagher and Gallagher, 2011; Peng and Nunes, 2009). These improvements are based within what Krackhardt and Hanson (1993) define as the informal organisation. This is an organisation in which work is undertaken within social networks that involve employees from across functions and divisions working together to accomplish tasks quickly. The benefit of informality is that it involves employees and leads to increased flexibility in meeting business needs (Morand, 1995).

Furthermore, literature on enterprise social software, often termed enterprise 2.0, also suggests that informal structured communication supports flexibility and helps deal with uncertainty (McAfee, 2006). However most of current ERP research focuses on the enterprise system project implementation (Woo, 2007; Ifinedo et al., 2010; Wagner, 2010) without revealing how a company use the system in the post-implementation stage. There is a gap in the literature in understanding the combination of the formality of ERP systems with the informality arising from employee's interactions. This study explores the use of a system approach combining both ERP and informality to enhance the interactions between frontline users and the ERP system in the system post-implementation.

The next section reviews the extant literature, setting the context of the research. Next, the methodology is outlined and a number of case studies are presented and analysed. Findings are presented and finally conclusions from the research are discussed.

\section{Literature review}

Most research in the area of ERP implementation is focused on how to increase production performance, rather than the issue of the effect on social interactions. However there is evidence that manufacturers suffer from rigidly designed ERP systems. For example these systems generate production plans through a manufacturing requirements planning (MRP) system, which has a fixed lead time to plan for purchasing order and production order, and cannot flexibly respond to changes in lead time (Moon and Phatak, 2005). These features of an ERP can result in material shortage, over-ordering or over production (Chen, 2001).

Recently, the importance of informal systems to provide better communication between people and enterprise systems has been realized, as technologies are never fully "stabilized" or "complete", due to innovations in areas such as material technology and establishment of new standards (Orlikowski, 2002). For example, Gebauer and Schober (2006) highlight the use of flexibility to support business processes to accommodate uncertainties in the competitive markets in a communication technology manufacturing firm. Bruno et al. (2011) describe an informal communication software application that is used in a manufacturing firm in order to increase flexibility and help deal with uncertainty by encouraging the involvement of experienced employees. Sociomaterial theory (Orlikowski and Scott, 2008) concerns ensuring that the relationship between knowledge and practice are mutually constitutive.

The term "informal" is originally from organisation management theory, and refers to the emergent patterns of business behaviour that are relatively "loose", "spontaneous" and involve "casual social intercourse and comportment" (Morand, 1995). Rules of conduct imply informal and implicit consents, such as customs, traditions, 
conventions, ethics and authoritative relations. Usually, informality is used to describe a firm which is loose, flexible and embeds human practices, rather than practical, holistic or logical (Kaman et al., 2001). Leonard and Higson (2014) refer to this as fluidity.

Table I lists a number of definitions of "informality" that are categorised into three dimensions of organisation structure, communication method and leadership approach as a management approach. Within the category of organisation structure Morand (1995) defines "informality" as a type of organisation that is organic and innovative with high involvement of social participants. A manufacturing firm also can be flexible and loosely structured (Parthasarthy and Prakash Sethi, 1992).

\begin{tabular}{lll}
\hline Category & Informality related definitions & Source \\
\hline Organisation structure & Informal as unique behaviours of organic and innovative organisation with & Morand (1995) \\
& high involvement of social participants & \\
& At the operational level, manufacturing structure can similarly be measured & Parthasarthy \\
& using dimensions of job design, operator job description, operator skills, & and Prakash \\
& design-manufacturing integration and so on. The respective dimensions are & Sethi (1992)
\end{tabular}
narrow job scope-multiple roles, formal/ planned-informal/flexible, specialized-diversified, and preplanned/sequential-on-line/parallel Informal organisation structure has been promoted in IS alignment to describe a third, perhaps hidden, component of alignment. It is comprised of various informal structures, that is, "relationship-based structures that transcend the formal division of labour and coordination of tasks". It comprises the various informal structures, connections and procedures that people use to get their work done, such as social networks, communities of practice, cross-department relationships, unofficial agreed-on processes, flexible division of work and such

Communication method Informal organisation is network, culture, communication of practice and the Foss (2007) like, rather than formal governance mechanisms. But if only an informal organisation is considered, there is a tendency to become less normative Informal organisation arises from the interaction of people working in the organisation, their psychological and social needs, and the development of groups with their own relationships and norms of behaviour, irrespective of those defined within the formal structure.

(1) the informal organisation is flexible and loosely structured;

(2) relationships may be left undefined;

(3) Membership is spontaneous and with varying degree of involvement Informality concept frequent used in ethnography of communication, in sociolinguistics, and in social anthropology to describe social occasions and the behaviours associated with them

Informal networks, networks of relationships that employees from across functions and divisions to accomplish tasks quickly enables to meet unexpected achievements by cutting through formal reporting procedures to jump start stalled initiatives

Informal communication often consists of unplanned and brief "catching-up" conversations among employees in organisations

Leadership approach Informal control is based on socialisation processes to ensure that the right people engage in contributing develop business values, beliefs and goals of firm, which consists of "clan-control" (group level with sufficient (Chan, 2002) and Prakash Sethi (1992) Mullins (2013, p. 95) socialisation) and "self-control" (individual-level exercises with freedom). It is based on social group or people empowered control mechanism, and spurs the values of social participants The empowerment of employees is a key factor for corporate innovation and for the use of Web 2.0 technologies (informal system) to support the exchange of ideas and organisational learning Informal knowledge that is generated in action, resides in individuals' minds and in stories shared in communication of practice, which is tacit, unstructured and un-codified

Irvine (1979)

Krackhardt and

Hanson (1993)

Zhao and Rosson (2009)

Elmes et al. (2005) and Hwang (2005)

Schneckenberg (2009)

Tsoukas and Vladimirou (2001) 
Chan (2002) states that the informal structure in information system (IS) research is a relationship-based structure which does not follow predetermined responsibilities and procedures, but focuses on the continuous alignment between management practices and IS strategies. Within the category of communication methods Foss (2007) and Mullins (2013, p. 95) find a "informality" network with a culture of communication of practice, without formal governance mechanisms, which arises from the interactions of people, their social needs, relationships and norms of behaviours. Thus, informal communications are unplanned social interactions, and supported by web 2.0 techniques (Zhao and Rosson, 2009). Within the third category of leadership approach "Informal control" concerns the need to empower knowledge workers so they can contribute to developing business values, beliefs and goals of the firm. An distinctive example is Elmes et al. (2005) and Hwang (2005) who highlight the informal control in ERP adoption that empowers workers to undertake working processes to increase system acceptance. Informal knowledge is related to this category on the basis of participative concept that allows the decision making of lower employees (Schneckenberg, 2009) and highlights the usage of individual's practical knowledge in business (Tsoukas and Vladimirou, 2001).

\subsection{Theory foundations}

The research is fundamental based on socio-technical-related theories. The socio-technical theory (STS) is that the theory supports both human participants and technology-performed processes that are essential in an organisation (Bostrom and Heinen, 1977b). This underpins the concept of a combining management system with both formal processes, in the use of ERP, and informal processes, in the participation of frontline employees. In addition, Clegg (2000) indicated the importance of humanistic systems in achieving superior results by ensuring all the subsystems in STS work in harmony. This is related to the informal perspective that emphasises the efforts of low-level employees because production systems are variable and uncertain.

However, the recently studies illustrate the importance of socially shaping technology in ERP research. Sociomateriality theory, in particular, defines the practices of the technical subsystem as being constructed by material and social entities, and they are inseparable (Orlikowski and Scott, 2008). That is to say, the social and technical sub- systems are not two isolate systems, but rather a fusion word - sociomateriality (Leonardi, 2013). Thus, the sociomateriality theory fundamentally supports this research.

Based on sociomateriality theory, the business practices are defined as two types: first, the practices in which people engage (i.e. organisational routines embedded in a system); and second, the practices of what people actually do (i.e. non-routinised behaviours).Orlikowski (2002) first coined the phrase "technology-in-practice", by which information technology is formulated gradually, based on people's practices. This theory concerning knowledge is inseparable from knowledge practices, and is constituted through situated actions. Rather than attempt to abstract action from its circumstances and represent a rational plan, the situated action depends on how people use their circumstances to achieve intelligent action (Suchman, 2007, p. 79). The situated actions are not formally predetermined, but rather are informally constituted by human beings.

Informal system (e.g. enterprise 2.0) are based on sociomateriality theory (e.g. Jarrahi and Sawyer, 2013). Social media are entangled in the social practices of people (Scott and Orlikowski, 2012), and influenced by the collective intelligence of human beings (McAfee, 2009, p. 139). Enterprise 2.0 supports informal communications to bind people beyond a formal organisational boundary. For instance, when ambiguity occurs, the enterprise 2.0 systems allow people to search their own social networks, rather than forcing them to use a pre-designed problem-solving tool (Cook, 2008, p. 90). However, an ERP system merely contains pre-determined formal descriptions of working processes (McAfee, 2009, p. 53), whereas an informal system facilitates the retrieval of social occasions and behaviours, which might support the situated actions that are achieved on each occasion of interaction with reference to situation particulars (Foss, 2007). This theory indicates that two systems that are complementary rather than contradictory, and underpins this research which supports an organisation with two types of business practice: pre-determining business activities (formal activities) and situated actions to perform business tasks (informal activities).

The authors also use the traditional STS concept to categorise the analyses of the benefits and challenges of using the combination system. From a traditional STS perspective, any organisational work system consists of technical 
and social subsystems (Bostrom and Heinen, 1977a), which suggests a need to evaluate the changes that are brought by an IS from the following dimensions:

- technical subsystem consists of the business processes and technologies to perform these processes, which transfer business inputs into outputs in such a way that the overall performance of an organisation can be strengthened; and

- $\quad$ social subsystem is composed of people and organisation dimensions, including people and their attributes, such as knowledge, skills, attitudes, values and needs, and organisational structure, power and policy.

However, there are some conceptual differences between the traditional STS and the systems in this research. This research focuses on ERP adoption in a business within an informal context. The multiple case studies illustrate that the informal system highlights tacit/uncodified knowledge and experiences of individuals in the social system and this is not the social subsystem defined in STS. Kumar et al. (1998) extends STS to illustrate the importance of the third dimension, including trust, social capital and collaborative relationships in addition to power and policy in traditional STS. Besides the socio-organisational context that considers IS innovation related to organisational change (e.g. structure, power, policy), Kumar et al. (1998) emphasises that the socio-cultural environment fosters a collaborative relationships that amounts to collective entrepreneurship. Relationship management and cultural issues are essential in the informal system that highlights the interactions between individuals and improves the well-being of people in an organisation. Thus, the author will bring in the third dimension socio-culture that focuses on analysing the cultural impacts by introducing the informality when a firm uses an ERP.

In summary, the reasons for the research are: first, existing knowledge of a combination system is remarkably limited, but there is a growing interest in firms using a combination system, rather than a single ERP; second, ERP and informal systems are, importantly, currently used by companies, and show some complementary features; and third, there are some related studies, but they do not theorise the value of combining formal and informal practices.

The research objectives of this research are: first, identify whether informality can be used along ERP systems; second, identify the characteristics of informality, when used along ERP systems; and third, describe what dimensions need to be considered when implementing ERP with Informality.

\section{Research methods}

\subsection{Research design}

The aim of this study was to "exploring" what happens after an ERP system is implemented in an informal organisation context. The type of organisation is organic and innovative, which is particularly applicable to an organisation in turbulent and uncertain environments, for example of the Chinese companies. Martinsons and Westwood (1997) suggest the Chinese organisational culture of uncertainty tolerance is arguably related to unstructured business process. There is already much existing research which merely focuses on the implementation of the ERP system and its IT functions, rather than exploring how the system is actually used by an organisation. Moreover, there is quite rare of existing studies take into account the importance of using an ERP system to match the business context of an informal organisation. According to Crewell (1998, p. 99), qualitative research pursues "what" and "how" questions to get a deeper understanding of an observations, which research questions tend to seek, to discover and explore a process, or describe experiences. This exploratory study suits for a qualitative research design.

The paper presents an empirical study of four manufacturing firms, which aims to collect varied empirical company context of the adoption of an ERP system with different problems. Yin (2009) suggested to use multiple case study method as the evidence from multiple case studies is considered more compelling. The organisation chosen are based on logic of replication (Yin, 2009, p. 56) in which the underlying logic of this method is replication, that is conducting a series of cases on related topics, with each case serving to confirm or disconfirm the hypotheses. These companies with broadly similar characteristics were chosen for this study. Many Chinese firms is in an informal and unstructured working manner. In the Chinese business culture, organisational coordination and control are achieved by informal, relational and implicit means, rather than by the formal, transactional and explicit approaches common 
to western corporate settings (Yeh and OuYang, 2010). Many of the enterprise system software such as SAP often conflicts with Asian ways of operating, or with its organisational culture (Strong and Volkoff, 2010).Therefore, the cases in this study are all Chinese manufacturing firms who have implemented ERP systems over an extended period. As illustrated in Table III, most of them have adopted the systems for over ten years.

\subsection{Data collection}

This research is based on semi-structured interviews of IT managers, senior managers and key users in June to September 2011. The interviews were designed to capture interviewees' experiences and perspectives regarding the enterprise systems that they implemented. Most of the interviews were conducted as group interviews, as the interviewees felt more comfortable in expressing their views and responding to the ideas of other interviewees around them (Easterby-Smith et al., 2008). This research conducted the interviews with a wider range of staff from different departments in order to collect data from three sections. The following table shows the individuals selected to be interviewed for each case and why they were selected. This study drew heavily on participants' experiences and interpretations, and hence the selection of interviewees was very dependent on their areas of expertise (Table Al). Following the theme, information from the case study research is corroborated by other data sources to ensure its validity, including company handouts, websites, presentations and organisation charts.

\subsection{Data analysis}

This study followed Yin's (2009, p. 156) cross-case analysis method. After collecting the data, data display and data reduction were used in analysing each case finding as the first step. This research summarises the key information of each case based on the interviews and document analysis. The second data analysis stage is a synthesis process that aggregates the key findings across all cases. This stage including outlined the main problems of each company while using an ERP system. Following this, the study defined the important characteristics of informality when a company uses an ERP to eliminate these problems. The third stage of cross-case implications included synthesising the propositions related to the benefits and challenges when companies come to use the combination of an ERP and informality. The third stage of cross-case implications included synthesising the propositions related to the benefits and challenges when companies come to use the combination of an ERP and informality.

\section{Case studies}

Table II shows context information of each case, including ERP implementation and organisation type. The sample includes manufacturers of food, display, water heaters and electronic goods located in China. Company $A$ is a Chinese local manufacturer and the remaining companies are subsidiaries of international companies. Most of them are middle and large sized firms with more than 1,000 employees with their scale of production having motivated all of them to implement ERP systems. All the firms have long established ERP systems with company $A$ and $C$ having improved their ERP systems in the 2000s.

Most of them have implemented standard ERP software packages of SAP ${ }^{\circledR}$ or QAD, while only company $C^{\prime} S$ ERP is fully customised for the manufacturer. Most of these firms use the production, procurement and planning functions of ERP in order to facilitate a smooth operation. Company $A$ is a traditional firm with all ERP functions, which also includes logistics, sales and finance. Company $B$ and $B$ have only production-related modules in their ERP systems. Company B uses a e-purchasing system through an electronic data interchange (EDI) platform to reduce supply chain risks. If company $B$ receives a change of production orders the system can the request raw materials or change the purchasing orders to suppliers immediately. Company $D$ is an innovative firm which uses a customer relationship management system and store management system to interact with the sales office to effectively predict production orders and to evaluate performance of each sales office with real-time sales information.

Most of the manufacturers are not familiar with informal systems, with only company $C$ using informal systems such as a Bulletin Board System (BBS) on a web platform to arrange informal group (IG) entertainment. The informal groups are unofficial clubs with groups of people that have common hobbies such as a swimming group or photographic group. The aim of the IG is to improve the collaborative work of employees from different departments and in the company they call the website "collaboration". An example of the use of this website occurs when HR managers devise process flow charts for the ERP system. Here they upload the process flow design to the 
website and retrieve feedback from all members of the tourist group, for example, including staff in the production department, technology department, administrative staff and the general manger.

\begin{tabular}{|c|c|c|c|c|}
\hline Company & A & $\mathrm{B}$ & $\mathrm{C}$ & $\mathrm{D}$ \\
\hline \multicolumn{5}{|c|}{ Company background } \\
\hline Production type & $\begin{array}{l}\text { Food (meat } \\
\text { process) }\end{array}$ & $\begin{array}{l}\text { Electronic equipments (i.e. } \\
\text { televisions, projectors, } \\
\text { LCD televisions) }\end{array}$ & $\begin{array}{l}\text { Display technologies } \\
\text { applied in digital, } \\
\text { communication devices }\end{array}$ & Water heaters \\
\hline Year of creation & 1993 & 1996 & 2002 & 1996 \\
\hline No. of employees & $3,000+$ & $1,000+$ & $1,000+$ & $1,000+$ \\
\hline Capital structure & $\begin{array}{l}\text { Local Chinese } \\
\text { manufacturer }\end{array}$ & $\begin{array}{l}\text { Sole corporation, } \\
\text { subsidiary of a Japanese } \\
\text { firm }\end{array}$ & $\begin{array}{l}\text { Sole corporation, } \\
\text { subsidiary of a Korea } \\
\text { firm }\end{array}$ & $\begin{array}{l}\text { Sole corporation, } \\
\text { subsidiary of a US firm }\end{array}$ \\
\hline \multicolumn{5}{|c|}{ The usage of the ERP system } \\
\hline $\begin{array}{l}\text { Start of adoption } \\
\text { year }\end{array}$ & $\begin{array}{l}1996 \\
2006 \text { (2nd } \\
\text { implementation) }\end{array}$ & 1997 & 2002 & $\begin{array}{l}19992009 \text { (2nd } \\
\text { implementation) }\end{array}$ \\
\hline Adoption method & $\begin{array}{l}\text { SAP standard } \\
\text { software+ ongoing } \\
\text { improvement by IT } \\
\text { dept. }\end{array}$ & $\begin{array}{l}\text { SAP (standard software } \\
\text { from } H Q \text { ) }\end{array}$ & $\begin{array}{l}\text { Customised system } \\
\text { based on Oracle by sub- } \\
\text { company (phased) }\end{array}$ & $\begin{array}{l}\text { QAD+self- } \\
\text { development to make } \\
\text { continuous } \\
\text { improvements by ERP } \\
\text { project team (phased) }\end{array}$ \\
\hline $\begin{array}{l}\text { Functional } \\
\text { coverage of the } \\
\text { ERPs }\end{array}$ & $\begin{array}{l}\text { Production, } \\
\text { purchase, plan, } \\
\text { sale, finance, } \\
\text { logistics }\end{array}$ & $\begin{array}{l}\text { Production, purchase, } \\
\text { planning, EDI }\end{array}$ & $\begin{array}{l}\text { Procurement, material } \\
\text { mgt., production + HR }\end{array}$ & $\begin{array}{l}\text { Production, purchase, } \\
\text { plan, material mgt., } \\
\text { finance, sale + } \\
\text { CRM }(3 C)+\text { store mgt. } \\
\text { system }\end{array}$ \\
\hline \multicolumn{5}{|c|}{ Informality characteristics } \\
\hline Informality & $\begin{array}{l}\text { Need but negative } \\
\text { attitude }\end{array}$ & Need and positive attitude & $\begin{array}{l}\text { Use (BBS communication } \\
\text { platform) }\end{array}$ & No need \\
\hline $\begin{array}{l}\text { Organisation } \\
\text { structure }\end{array}$ & Hierarchical & Team work & $\begin{array}{l}\text { Team work and loose } \\
\text { structured with informal } \\
\text { groups }\end{array}$ & Hierarchical \\
\hline $\begin{array}{l}\text { Communication } \\
\text { method }\end{array}$ & Top down & Top down & Bottom up & Bottom up \\
\hline $\begin{array}{l}\text { Leadership } \\
\text { approach }\end{array}$ & Formal, rigorous & Formal, rigorous & Empowerment & Empowerment \\
\hline
\end{tabular}

Table II. Characteristics of Chinese manufacturing companies

In order to investigate the informal nature of these firms, the interviews are designed based on three key characteristics of informality. The organisation structure of company $A$ and $D$ are hierarchical, while company $B$ and $C$ are based on flat organisation structure with an emphasis on team-work. Company $A$ and B's communication method is top-down with formal and rigorous leadership approach, as they have a patriarch-based management. What is more, company B is only treated as an international factory with systems and production orders assigned from a corporate headquarters. Company $C$ and D's internal communication atmospheres are open and encourage employees to join in key business decisions. Both of their management philosophies highlight the need for commitment from employees. Moreover, company C proposes a "fun" workplace and defines effective communication with employees as its' management slogan.

\section{Findings}

A major outcome of this research is to conceptualise the concept of informality for manufacturers implementing ERP systems. This is achieved by an analysis of the case study data in relation to the three characteristics of informality defined from the literature of organisation structure, communication method and leadership approach. The 
outcome of this analysis is a conceptualization of informality using four dimensions relevant to the context of implementation of ERP in the manufacturing companies.

\subsection{Informal knowledge}

Both of company A and B met the problem that firms' system performance does not consist of the practices in real world. Company A has an SAP ERP system, but the delivery module cannot be satisfied for all delivery situations, which can cause mistakes in delivery. According to the IT manager at the company:

The logistic system systemic analyses and calculates the weight of each production lot. However, in practice the company has made mistakes in delivery. For example, the delivery carrier found that the initial system designer had forgotten to calculate the size of the delivery box. Sometimes, workers arrange the delivery job by themselves. Nearly every 6 months senior managers noticed the problem and realized they needed more flexibility and timely changes in order to react to the problems that are experienced by end users.

The similar problem has occurred in company B, its ERP system was promoted by Head Office in Japan, which did not align with the working context in the factory. The advanced systems of EDI-supported SCM in ERP benefit a firm in interacting with suppliers with real-time information in order to reduce the impact of urgent orders. Yet the system did not work in the context of a Chinese factory. According to the Production manager:

[...] We want to reduce production pressure through this form of communication (EDI), but it is hard to implement it now. In China, most suppliers do not accept frequent changes to orders. It is impossible for some small suppliers without sufficient computing and networking supports to work with the systems. They do not accept frequent changes to the orders, as they also have their suppliers, and the changes will affect on the entire supply chain [...].

Both two manufacturing firms shows when an ERP system is used, the practical knowledge of system participators is valuable and contributes to aligning the system performance and the understanding of the operations in the real world. We define this dimension of informality for manufacturers close related to the "technology-at-work" concept introduced by Orlikowski and Scott (2008). This concept highlights the need for an ad hoc process for knowledgeintensive management. The first finding related to the "technology-at-work" concept means bringing the practical knowledge of shop floor employees to align the system-based practices and business reality. The organisation context motivates to employees share "informal knowledge" that resides in individuals' minds, which is tacit, unstructured and un-codified (Tsoukas and Vladimirou, 2001). In using ERP at post-implementation stage, preventing this inconsistency requires involved informal knowledge, because it brings in the knowledge embedded in employees' minds who directly work with the system (Table III). This is usually involves the continuous shape or reshape the ERP systems to align with the practices in the real world.

However, informality is more than the concept. When these two firms met the inconsistency between the system and reality, they showed different attitudes because of the different organisation structures (Table II). As company A Group's Operation manager commented:

Changes run faster than plans. But we still trust to plans, because inappropriate change is worse than no change.

For the senior manager's perspective, the company has high-volume production tasks. In such a large manufacturing firm, one inappropriate action would damage the whole production chain. This is the reason why the firm prefers to lose the orders over nearly six months rather than take action as soon as delivery workers report the problem. As illustrated in Table II, company A is based on a hierarchical organisation with a formal reporting system. Even if sometimes frontline employees are keen to participate in the improvement of using an ERP system, the long delay for a response from management will decrease the enthusiasm of the employees.

Company B is also a large manufacturing firm, but a team-based organisational structure enables the firm to work informally to some extent. The factory allows unforeseen changes in the orders to be tackled flexibly. The Production manager was positive towards informality: 
The production process is standardised. Each stage of production is according to the standards in the SAP system, but this does not mean that the details involved in each person's operations can be standardised. It means that you won't be able to standardise every single part of what goes on in the company [...] HQ might increase the production tasks in the some months. When production department receives the updates of production orders. Our production capacity isn't enough, material management department may maintain a certain amount of an extra stock to make up for this lack of production capacity [...].

At company B, the HQ promoted EDI system cannot solve the unanticipated changes in productions. the system did not work in the factory context of a Chinese factory, given that suppliers could not cooperate with the system without sufficient technology support, and they did not agree to alter their operational approach to fit in with the company B. Due to this particular operating environment and the resistance of stakeholders to join the new technical platform, the factory was not able to enjoy the full support of ERP systems. The business environment requires company $B$ tolerating the production uncertainties by using its own approach - maintaining a safety in this firm to solve the variability in orders

\begin{tabular}{llc}
\hline The characteristics of informality & The benefits of having informality in a company when it uses an ERP & Case example \\
\hline Informal knowledge & Technology at work and flexibility-to-use & Company B, C \\
Informal control & Empowerment and participative management & Company A, B \\
Informal communication network & Coordination and collaboration & Company A, C \\
Informal process & $\begin{array}{l}\text { Flexibility in operation to respond to unexpected/ unique } \\
\text { circumstances }\end{array}$ & Company A, B, C
\end{tabular}

Table III. Characteristics of informality in a company which uses ERP

Regarding to IS management, there are two type of flexibility in IS of "flexibility-to-use"and "flexibility-to-change". The former one is defined as integrating a range of process requirements into an IS without major changes to the system itself, while the latter one is required to change a given IS (Gebauer and Schober, 2006). Flexibility-to-use is moreappropriate in this case, in that it allows system users to flexibly and effectively adapt their way of responding to the unexpected orders. Besides "technology-at-work", informal knowledge in this paper is also related to the concept of "flexibility-to-use" (Table III).

Informal knowledge allows users to flexible make changes in the production in order to respond to uncertainties immediately, rather than following a serious of structured and system-based production practices.

\subsection{Informal control: empowerment (rigorous control)}

Nonetheless, an adequate culture context is more important to achieve the informality. Both company $\mathrm{B}$ and $\mathrm{C}$ are multinational manufacturing firms, and their production tasks are designated by $\mathrm{HQ}$ without any directly interactions with the sales office. Therefore, they both faced to deal with unanticipated production orders. However, company B encountered much more problems because of informality, and company $\mathrm{C}$ successfully coped with its production uncertainties, because of different leadership approaches in these factories (Table II).

As indicated in the above example, company B tried to solve the production uncertainties by using of safety stock; however, the firm met the false inventory problem in its ERP system, and sometimes, its ERP comes to a halt when the stock information does not synchronise with reality. As the technical department manager recalls:

At the end of every month the Head Office in Japan carries out an evaluation of every production site, one of the major indicators of which is the inventory. For example, if the production value for that month is 1.5 billion and we also have 1.5 billion in stock, that's ok. However, if we have 2 billion in stock, then there's a problem. So we cannot input the extra material information into the system directly, We will wait for the following month to add extra material information into the system, so that next month the actual amount of purchasing order is less. Sometimes, the production plans from the system might be in a mess!

The factory B works under the context of "ERP enabled manufacturing control". According to Kallinikos and Hasselbladh (2009), work and control regimes are currently subject to significant transformation as computational technology expands its regulative aspirations, entering every walk of life. This perception is confirmed in this case by the fact that Head Office monitors and controls production flow, cash flow and material storage of the factory, and even sets standards with respect to inventory and expense by using the ERP system. In order to follow the inventory 
standards in the ERP, personnel cannot input the real stock information into the system in order to achieve the required inventory. Eventually, the planning and calculation module in the ERP systems cannot be used, since the information does not synchronise with reality.

In contrast to company $\mathrm{B}$, company $\mathrm{C}$ has more anticipated production problems. Besides the unanticipated production tasks, the company might face to the problems of low-quality goods and losing or damaging goods due to delivery because its goods are fragile. However, the manufacturing firm achieved to the flexibility towards the production uncertainties, as it uses of an informal system - online BBS discussion forums called as collaboration. The informal system supports of the direct communication between top managers and frontline employees. The employees have a strong sense of belonging and loyalty, as the company's management styles empowers employees to express their ideas and suggestions, thereby facilitating an informal communication network. The HR manager emphasised the definition of "respect" in the company:

Our CEO has talked about the concept of the DNA of LG before. Talent is the DNA of LG [...] if I obey an instruction from my superior, at the same time I have the right to express my opinions. This is called "respect" in our company [...].

When company $\mathrm{C}$ faced the production uncertainties, its production department will put a notice on the its internal website, all members of entire organisation will see it and discuss the solutions through its BBS discussion forum. The company is able to coordinate personnel from diverse fields of the organisation. The company may either work overtime, improve its production lines or modify the stock-level requirements in the ERP system. The top manager does not restrict on the ways of solving the production problems, and even they directly communicate with frontline employees through informal system platform regarding to the problem solutions.

According to Ignatiadis and Nandhakumar (2007), "too much control can serve to streamline the operations of a company, but at the same time can decrease the resilience of the company to respond to future changes". Case B faced the problems of unanticipated changes of the production orders. However, due to "rigorous" control embedded in the ERP system, the organisation experienced misalignment that the system does not synchronise with reality (Table II). Even worse, turbulent operation occurred because of inconsistent information in the system to support day-to-day operations. If the ERP is used in a control-driven context with formalised working processes that misaligned with the sub-units' organisation context, it will disrupt operations in an organisation. By contrast, the "empowerment" is highlighted in company C, company C is able to make the changes as it needs (Table II). Therefore, informal control in ERP post-implementation stage enhances an organisation with the culture of participative management that motivates individuals to invent new materials, establish new working standards or modified the contents of the enterprise system (Table III). This is especially important when the firms need to cope with the various unanticipated production problems.

\subsection{Informal communication: trusted human networks (lack of communication)}

Compared to company $A$ and $B$, company $C$ has an harmonious working environment but any benefits gained from informality are unintentional. The working environment motivates the development a social networks within the organisation, and the communication methods trends to be bottom-up rather than top-down (Table II).

The staff in company A complains about the top down communications brought by an ERP system. In 2006, Company A has the second improvements on its ERP that developed the sales modules, which supports the firms to segment customers groups based on sales region and price, after inputting the customer name, sales region and phone number into the system, the price, promotion contracts, credit allowance and arrears will be shown. If the customer has no arrears, the sales office will sell goods based on price standards. As a result, the sales office has been able to with thousands of customer orders, and efficiency has increased tenfold. The function of ERP benefited senior managers in checking up on all sales prices in a timely fashion, and make a rational price range for a product based on historical sales records. However, the rigid price standards in the system do not always work. The sales office manager said:

For example, during holiday promotions, unsaleable goods promotions, new production and new shop promotions, we might need to break the restrictions on price range [...]. 
The sale manager complains about the modification of price standards is allowed. If there is any new sales discount, the discount may be activated after the order is effective. The change is only undertaken after formal approval procedures in the system. However, the sales office is not able to timely change of the production price depends on its market and stock conditions after implementing the ERP systems.

Company $\mathrm{B}$ and $\mathrm{C}$ works in a similar condition: they both are the Chinese factories of the multinational firms, and have few interactions with their sales offices located in all over world. Nevertheless, the communication environment of factory $\mathrm{C}$ is much better. Informal system (i.e. BBS) supports on the horizontal communications between the employees from diverse fields. For instance, the IT manager, Production manager and

HR manager discussed how the firm could deal with these uncertainties:

We can either work overtime, or can reschedule the production plan [...] (IT manager).

[...] From our HR's perspective, working overtime is difficult to implement, as most of the employees are not willing to do so [...] (HR manger).

[...] The planning department are not willing to reschedule the production plan, as it is complex and takes time to re-run the MRP and purchasing plan for the whole orders. Sometimes, the production department complains that there is not enough capacity on the production line to do the additional orders [...]

(Production manager).

[...] So we have a group called "TASK" composed of a few people from different departments to work together and to discuss the best solution for the issue. The people in the "TASK" group also link with the other colleagues in the IG. Sometimes, nearly all the employees sit together to discuss the solution through our "collaboration" platform (online discussion forums- BBS) (IT manager).

To persuade employees to collaborate together, informal communications are remarkably effective. As Zhao and Rosson (2009) stated, "interpersonal trust" between social participants leads to informal interaction based on social arrangement and emotional loyalties; this in turn can coordinate all participants in social networks and increase the feeling of intimacy and connectedness between colleagues. The networks here are not merely a physical communication platform, but also an organisational climate that supports emotional interactions and establishes social relationships. The solution to the uncertainties is found through collective members. According to the HR manager:

[...] Teamwork is very important, and the method by which it is achieved is that the manager requests that the two people get along well, or do they take the initiative themselves? It's very obvious how two people unconsciously grow closer together, when they're very at ease with each other, and it's very easy for them to coordinate their work.

Thus, the company developed IG is an unofficial organisation for employees with shared hobbies: for instance, a swimming group, photographic group, electronic game group and so on. However, unexpected benefits for IG are achieved, since the online forums connect employees from different departments. Employees call the website with the discussion forums a "collaboration". The platform is not merely intended to arrange social activities and entertainments, but also for business communications, for example of discussing the solution of the unexpected production orders.

In many of Chinese firms, their organisation culture is related to informality. Sometimes, it is represented as lack of formality in business process and planning. Thus, the use of ERP system benefits these firms to improve the resource allocation, enhance efficient processes and make the rationale operation plans (company A). However, informality embedding in the culture also can be represented as reliance on networking, relationship, intuitive decision making. The informal social relations is called "guanxi" in the Chinese, which is based on personal social network. As Marble and Lu (2007) stated, "Chinese business practices are based on guanxi (personal social network), which is heavily reliant on informal (primarily oral) rather than formal (written) interchange". In fact, the Chinese organisational management system is not formal and rule based, but tacit and informal, based on subtle social relationship codes (Martinsons and Westwood, 1997). The finding of Case C illustrates the importance of "informal communication" to 
collaborate personnel from diverse fields (Table III). The communication is not only supported by an informal system, for example of the online discussion forums in company $C$, but also the social relationships. The informal system is able to collect informal knowledge, that is, tacit and uncodified knowledge based on personnel's experience, because of the intimate relationships between the employees. This can complement the limitation of the formal enterprise system - the ERP only focuses on the collection of formal knowledge (documented knowledge) in a system database. As a consequence, the combination system benefits the firm co-ordinates operations with aligned actions in different functional departments by using the ERP system, and achieves cooperative operations among individuals in disparate fields, so as to produce a solution to unforeseen circumstances with diversified views.

\subsection{Informal process}

Finally, the communication environment of company $C$ and $D$ are similar that encourages empowerment and effective communication for employees (Table II). Yet, company $\mathrm{C}$ requires an informal system to react unexpected production problems, whereas company $\mathrm{D}$ skilled in managing the ERP system that respond to uncertainties proactively.

Company $D$ has relatively low levels of uncertainty and is able to deal with that uncertainty proactively. As the company has a world-wide reputation, many retailers are eager to sell their goods and in order to manage the sales offices effectively they implement a store management system which interacts with the sales sites directly. The system contains a large database of historical sales information of each sale office that is used to predict demand and link with the ERP planning systems. In addition as a retailer places an order through the platform, the system links with the ERP to generate a production plan for actual demand. About the level of uncertainty the production manager states:

Even if there is some unpredictable orders, the amount is quite small. And their policy is to provide goods for customer in two weeks. Usually, they can finish the work in 2 weeks with over-time work.

So the occurrence of uncertainty is low in this company, as its work processes in the ERP are frequently improved by the technical department because the technical department and production departments work together and have frequent interactions. Informality here is related to the "informal organisation structure" coined by Chan (2002), which is important in improving IS alignment and performance. The organisation structure is a relationship-based structure that transcends the formal division of labour and coordination of tasks. Rather than having merely a strict adherence to predetermined responsibilities and procedures, company $D$ frequently has interactions between technical development and low-level employees, so as to align the design of an ERP to the business realities. Company $D$ is able to improve the system capability to cope with business uncertainties in a proactive manner. Therefore, the senior manager stated that informality does not need in this company, since the firm is in a stable business environment.

Nevertheless, as Suchman (2007, p. 69) pointed out, situated actions are important as well since people always act within a present situation and find it difficult to be aware of a situation ahead of time, at least not with any specificity. A reactive strategy is appropriate to meet unexpected events and unique opportunities (Madnick, 1991). Company $B$ and $C$ works with the reactive strategy since there is no direct communication between the factory and sales office. Although company A also works proactively to the uncertainties in demand with a demand forecast module in the ERP system, the firm still complains about the forecasting errors of its ERP. Not all changes in demand can be predicted. As the IT and Operation manager stated:

However sometimes, the forecast demands and the actual demand are different, particularly during festivals and holidays.

Therefore, "informal process" is still requisite to react to unpredictable changes in production based on frontline employees' experiences (Table III). Nonetheless, it should be note that the informality is more acceptable in a firm with reactive strategy, rather than being proactively.

\subsection{The definition of informality when a manufacturer implements an ERP}

Looking at the case study findings analysis in relation to the definitions of informality gathered from the literature review has been able to summarise informality in ERP post-implementation for these four aspects. 
Informality is considered with four characteristics which correspond to four constraints in adopting ERP:

- informal knowledge is the embedding of the practical knowledge of frontline employees in ERP systems to mitigate the inconsistencies between system-based performance and practices in the business;

- informal control highlights the development of empowerment and participative management in an organisation, so as to align the system-based practices and business reality;

- informal communication network involves personnel from different departments cooperating to solve unforeseen problems in ERP implementation with diversified viewpoints; and

- informal process enables knowledge-based work procedures to be applied in the

- $\quad$ ERP system to tackle exceptional situations with the appropriate practices.

\section{Discussion}

The above case studies present different attitudes towards adopting an ERP in an informal working context. The analyses of diversified perspectives is on the basis of STS system (Bostrom and Heinen, 1977b) which illustrates the emerging propositions related to the benefits and challenges of implementation of the ERP and informality from technical, socio-organisational and socio-cultural dimensions:

- the technical dimension focuses on the performance of the hybrid system and business tasks;

- the socio-organisational dimension is related to the hybrid system and its impact on an organisation; and

- $\quad$ the socio-cultural dimension emphasises system users' perspectives on the influence of a system, with a particular focus on the cultural factors in adopting a system.

\subsection{Technical dimension}

The usage of informality along with an ERP might improve the flexibility to the production uncertainties, but there could be a trade-off between efficiency and flexibility in operation when a company come with both the ERP and informality.

The combination of informality and ERP-based management approach in a company presents the benefits of overcoming the inflexibility of the rigidly designed ERP with planning processes. The example of Case B illustrates the limitation of an ERP with the formal processes that inflexibly provides courses of action according to the business environment. The variability in customer orders cannot be solved by utilising a pure ERP with formally defined procedures. The informality benefits on support flexibility in responding to the variability and uncertainties in the organisation. The informal activity of Case $\mathrm{C}$ is in the role of supporting flexibility in operations by inspiring the engagement of employees. The informal system at Case $\mathrm{C}$ allows frontline personnel to tackle exceptional situations, unforeseeable events, unpredictable situations, high variability and high-complex tasks. At Case $C$, the informal working activities based on frontline employees' experience flexibly make adjustments to the production processes in order to fulfil the varied customer demands. The personnel from disparate fields can share their knowledge on the informal communication platform, so as to achieve flexibility in response to business uncertainties.

However, trade-off theory challenges the proposition that overall performance can be improved by implementing the combination system management approach. According to Slack and Lewis (2008, p. 145), there can be a tradeoff between cost efficiency and flexibility when implementing process technologies. The technologies automate the business process, and reduce operation costs effectively by repeating tasks with precision, speed and power, while being less flexible to changes. Human interventions in the operation remain the flexibility in a firm to cope with demand uncertainty and variability in the marketplace, whereas more costs arise because of the need to control skill and human creativity. According to Slack and Lewis (2011, p. 182), ERP is a process technology that directly impacts on the resource inputs in the operations in the business, as well as enabling the system to automate business processes, with the goal of integrating information process across the enterprise (Møller, 2005). The case studies of company $\mathrm{C}$ also indicate the potential problem of trade-off between efficiency and flexibility. The informality supports bringing in human wisdom in operating business to solve problems, and continuously aligning system- 
based business operating approaches and reality at company $\mathrm{C}$. Yet, this may result in substantial costs, as more employee costs are involved in day-to-day operations. Therefore, how to achieve a balance between emphasising the efficient, speed and physical abilities of automation by implementing the ERP against the flexible, intuitive and analytical abilities of informality by human interventions could be a potential problem in the adoption of the informality when companies used ERP system.

As indicated by Gulati and Puranam (2009), gaining value from both formality and informality by weighing up the costs and values of both. The author may note that the company needs to carefully weigh against the possible impairment in its ability to execute the informality in production by expanding the functional ERP system. In additional, Greasley (2013, p. 61) stated the performance of a process technology is required to align with key performance objectives. A company can have these two system approaches, but it needs to continuously evaluate its system performance in accordance with its primary operational strategies.

\subsection{Socio-organisational dimension}

The informality enables a company to align with system-based performance and reality; however there is a risk of inappropriate implementation of informal activities that are only based on frontline employees' experiences.

The social dimension of STS theory examines how technology enables business transformation by considering individuals' knowledge, skills, attitudes, values, needs, work environment as well as authority structure and reward system (Bostrom and Heinen, 1977b; Bostrom et al., 2009). The study in this dimension focuses on analysing the "transformation", which enables by using the informality when a firm works with an ERP system.

The above case studies present the benefits of embedding an informal system in an ERP which will result in aligning system-performed processes and human behaviour in practice, because human behaviour will influence the implementation of ERP systems. In regards with sociomateriality theory, the opportunity to combine two systems is indicated by Orlikowski and Scott (2008) that emphasises how daily practices are constructed by materiality (i.e. ERP) and social entities (i.e. informality). Moreover, the practices of "what people are engaged with" and "what people actually do" are both important in an organisation. Formal practices are in relation to plans, as representations come precisely from facts, which cannot be operations embedded in an ERP. However, systems cannot represent all those practices and circumstances in detail (Suchman, 2007, p. 74). Thus, a company needs informal activities related to the intelligences of human being to respond to different working situations. Therefore, this paper proposes that an enterprise system should contain both "formal practices" that are institutional procedures pre-defined in an ERP system and "informal activities" that drawn upon accomplishing specific activities by specific personnel to cover business uncertainties. For example, the situated actions are important to respond to unpredictable orders/emergencies in both company B and C.

Nevertheless, Orlikowski and Scott (2008) also pointed out, human behaviour influences information technology in organisations, and vice versa. An informal system in ERP systems aligns system performance and practices, while informal practice might not be aligned with "best practice" in the ERP that is governed by managers.

The company A senior manager pointed out that inappropriate action due to the informal system might lead to damaging the entire production chain, as informal practices are only based on the experience of employees. Company $B$ is an example of the inappropriate use of informal practice when the factory faces problems in inventory management. The data of the inventory management system is inconsistent with real stock, as personnel did not enter the safety stock information in the ERP system immediately. This was because over-stock would impact on the monthly performance evaluation in the production plant that assesses whether the materials and final products in the stock were in accordance with the production schedules in the ERP. As a consequence, the firm was unable to use the plan and calculation module of the ERP until employees manually amended the inventory in the system when there was another order. This perspective shows the risk of adopting an informal system along with ERP. ERP software is linear, and the information is provided according to prescribed algorithms so as to maintain the operation in a reasonable pattern (Lengnick-Hall et al., 2004), while informal practice may be inappropriate in its implementation and being incompatible with the performance of the ERP (company B). Ultimately, experiencedbased activities misfit with strategic governance by managers, as they are spontaneous, radical, fragmented and emergent, which might lead to a more serious operational problem. 
Unplanned activities are inconsistent with operating an ERP with well-organised activities. The misalignment derived from changes in formal practice in an ERP lead to missing important information to run the ERP properly (Sia and Soh, 2007). This is not because of making such changes, but rather due to the fact that there is no record of information related to changes in an ERP, and no formal guidance for managers. For instance, the problem does not exist in company $C$, because the general manager of company $C$ approves the changes in the ERP production plans to solve production uncertainties before actioning them. After being authorised, informal activities can be implemented, the information related to the informal activities are transferred to the ERP central database. Therefore, the prerequisite is to undertake the informal activities under the guidance of managers. If informal activities are implemented under managerial guidance, a firm is able to follow the data related to these activities, to avoid "misalignment".

\subsection{Socio-cultural dimension}

The implementation of the ERP and informality simultaneously could encourage the appearance of ambidexterity (both coordination and collaboration) in the organisation, but there will be a risk of co-existence of two types of culture.

The third dimension, that of socio-cultural study, emphasises the analysis of cultural factors in adopting an information system with respect to a "cooperative relationship" (Kumar, 1998).

Ambidexterity means that an organisation achieves complementary benefits (Gulati and Puranam, 2009) through structures-formalized which are loosely connected to rules and standards, which allows for combining unrelated matrices of knowledge in the business by encouraging informal communications (Chang and Hughes, 2012). The perception was also confirmed by the interviewed company (company C), who used ERP to coordinate the activities in the different functional groups. Formal rules and standards are important in customer services and goods quality checking-related processes. At the same time, informal organisations were also promoted in the firms that coordinate people from disparate functional departments Socialisation and interactions outside the boundaries of the organisation's structure were encouraged by the firm in order to develop a collaborative environment in the organisation. Informal communication and knowledge-sharing occurred spontaneously in the informal organisation, and people from different departments could deal with the urgent production orders effectively by discussing the problem from different standpoints. Thus, ambidexterity in this case means achieving complementary benefits in terms of both coordination and collaboration by using both the ERP and informality.

However, multiple management approaches co-existing in an organisation can be quite challenging. Company $D$ does not need the informality, since the company works in a stable environment, and being proactively to production certainties. Its advanced ERP is beneficial in mitigating the occurrence of uncertainties by analysing historical operational information. To some extent, the business situations may go beyond forecasting and planning, and informality as a management approach highlights the decentralisation and empowerment that can facilitate dealing flexibly with uncertainty, based on human intelligence. However, working informally in company D means a transfer of its organisational culture from being proactively to reactively. Therefore, the usage of the combining system approach needs to consider the consistenance with the existing organisational culture environment.

\section{Conclusion}

Unlike existing research, which is focused on enterprise system project implementation, this paper contributes on revealing the stories after the ERP system is implemented and how the manufacturing companies use the system to cope with the production uncertainties in China.

The main contribution of this paper is that defines the concept of informality and describing the notion of a system management approach combining informality and ERP systems, based on empirical research from four manufacturing case studies. The existing ERP systems are limited due to their operation around a fixed design production process and a fixed lead time to production plan and purchasing plan. The case studies present a range of applications of ERP and are analysed in terms of the three characteristics of informality, namely, organisation structure, communication method and leadership approach. The findings suggest that systems consisting of informality in combination with ERP systems can elicit knowledge from frontline workers leading to timely improvements in the system. This is achieved by allowing users to modify work procedures or production orders, and 
to support collaborative working among all employees. However it was found that informality is not required for manufacturers with a relatively stable environment who can deal with uncertainty with a proactive strategy. Four dimensions of informality that relate to manufacturers implementing ERP are defined as "technology in practice", "user flexibility", "trusted human networks" and "positive reaction to uncertainty".

However, before using the informality along with an ERP in practice, a manager must be aware of its benefits and challenges. The paper also provides practical contribution of how to utilise the informality effectively. The distinctive benefits are that of achieving flexibility in coping with uncertainties; reducing the misalignment between systembased activities and reality, and increasing coordination and collaboration within an organisation. Nonetheless, the usage of the combining system management approach may be risky in trade-offs between efficiency and flexibility, work inappropriately in that emphasises too much on experiences, and the inconsistency between current organisation culture. Following this, the paper recommends considering the consistency in the current working environment before introducing informality in a company. If a company really needs the informality, in needs to measure current business performance continuously and align current performance with required operation objectives to eliminate the trade-off operation risk with two management systems. Third, a company needs to undertake the informal activities with the guidance of senior managers in order to avoid the poor performance caused by misalignment with the overall strategy of a company.

The main shortcoming is generalisability, insofar as only Chinese firms participated in providing small samples of indepth data. This study primarily studied the organisational nature of informality, which focused solely on Chinese firms. This might result in restricting the application of the findings to future research. Many Chinese firms work in an informal and unstructured way because of the importance of working with multiple standards of business behaviour. However, many other organisations (e.g. small firms in developed countries) work informally in order to make continuous improvements in working practices (Coyte et al., 2012) and incremental innovation (Bos-Brouwers, 2009). Therefore, whether a hybrid system is as useful in other informal organisations in other countries would need to be established in future studies.

\section{REFERENCES}

Bos-Brouwers, H.E.J. (2009), "Corporate sustainability and innovation in SMEs: evidence of themes and activities in practice", Business Strategy and the Environment, Vol. 19, pp. 417-435.

Bostrom, R., Gupta, S. and Thomas, D. (2009), "A meta-theory for understanding information systems within sociotechnical systems", Journal of Management Information Systems, Vol. 26, pp. 17-48.

Bostrom, R.P. and Heinen, S.J. (1977a), “MIS problems and failures: a socio-technical perspective, part II: the application of socio-technical theory", MIS Quarterly, Vol. 1, pp. 11-28.

Bostrom, R.P. and Heinen, S.J. (1977b), "MIS problems and failures: a socio-technical perspective. part I: the causes", MIS Quarterly, Vol. 1, pp. 17-32.

Bruno, G., Dengler, F., Jennings, B., Khalaf, R., Nurcan, S., Prilla, M., Sarini, M., Schmidt, R. and Silva, R. (2011), "Key challenges for enabling agile BPM with social software", Journal of Software Maintenance and Evolution: Research and Practice, Vol. 23 No. 4, pp. $297-326$.

Chan, Y.E. (2002), "Why haven't we mastered alignment? The importance of the informal organisation structure”, MIS Quarterly Executive, Vol. 1 No. 2, pp. 97-112.

Chang, Y.-Y. and Hughes, M. (2012), "Drivers of innovation ambidexterity in small- to medium-sized firms", European Management Journal, Vol. 30, pp. 1-17.

Chen, I.J. (2001), "Planning for ERP systems: analysis and future trend", Business Process

Management Journal, Vol. 7 No. 5, pp. 374-386.

Clegg, C.W. (2000), “Sociotechnical principles for system design”, Applied Ergonomics, Vol. 31, pp. 463-477.

Coyte, R., Ricceri, F. and Guthrie, J. (2012), "The management of knowledge resources in SMEs: an Australian case study", Journal of Knowledge Management, Vol. 16, pp. 789-807.

Easterby-Smith, M., Thorpe, R. and Jackson, P.R. (2008), Management Research, Sage Publications Ltd, London.

Elmes, M.B., Strong, D.M. and Volkoff, O. (2005), "Panoptic empowerment and reflective conformity in enterprise systems-enabled organizations", Information and Organization, Vol. 15 No. 1, pp. 1-37.

Foss, N.J. (2007), “The emerging knowledge governance approach: challenges and characteristics", Organization, Vol. 14 No. 1, pp. $29-52$. 
Gallagher, K.P. and Gallagher, V.C. (2011), “Organizing for post-implementation ERP: a contingency theory perspective”, Journal of Enterprise Information Management, Vol. 25 No. 2, pp. 170-185.

Gebauer, J. and Schober, F. (2006), "Information system flexibility and the cost efficiency of business processes", Journal of the Association for Information Systems, Vol. 7 No. 8, pp. 122-147.

Gulati, R. and Puranam, P. (2009), "Renewal through reorganization: the value of inconsistencies between formal and informal organization", Organization Science, Vol. 20, pp. 422-440.

Hwang, Y. (2005), "Investigating enterprise systems adoption: uncertainty avoidance, intrinsic motivation, and the technology acceptance model”, European Journal of Information Systems, Vol. 14 No. 2, pp. 150-161.

Ifinedo, P., Rapp, B., Ifinedo, A. and Sundberg, K. (2010), "Rationships among ERP post-implementation success construct: an analysis at the organization level”, Computers in Human Behavior, Vol. 26 No. 5, pp. 1136-1148.

Ignatiadis, I. and Nandhakumar, J. (2007), "The impact of enterprise system organisational resilience”, Journal of Information Technology, Vol. 22, pp. 36-43.

Jarrahi, M.H. and Sawyer, S. (2013), "Social technologies, informal knowledge practices, and the enterprise", Journal of Organizational Computing and Electronic Commerce, Vol. 23, pp. 110-137.

Kallinikos, J. and Hasselbladh, H. (2009), "Work, control and computation: rethinking the legacy of neo-institutionalism”, in Meyer, R.E., Sahlin, K., Ventresca, M.J. and Walgenbach, P. (Eds), Research in Sociology and Organisations, Emerald Group Publishing Limited.

Kaman, V., McCarthy, A.M., Gulbro, R.D. and Tucker, M.L. (2001), "Bureaucratic and high commitment HRM in small service firms", Human Resource Planning, Vol. 24 No. 1, pp. 33-44.

Krackhardt, D. and Hanson, R.J. (1993), “Informal networks: the company behind the chart”, Harvard Business Review, Vol. 71 No. 4, pp. 104105.

Kumar, K., Van Dissel, H.G. and Bielli, P. (1998), "The merchant of prato-revisited: toward a third rationality of information systems", MIS Quarterly, Vol. 22, pp. 199-226.

Lengnick-Hall, C.A., Lengnick-Hall, M.L. and Abdinnour-Helm, S. (2004), "The role of social and intellectual capital in achieving competitive advantage through enterprise resource planning (ERP) systems", Journal of Engineering and Technology Management, Vol. 21, pp. 307-330.

Leonard, J. and Higson, H. (2014), "A strategic activity model of enterprise system implementation and use: scaffolding fluidity", Journal of Strategic Information Systems, Vol. 23 No. 1, pp. 62-86.

Madnick, S.E. (1991), "The information technology platform”, in Scott morton, M.S. (Ed.), The Corporation of the 1990s: Information Technology and Organizational Transformation, Oxford University Press, New York, NY.

Marble, R.P. and Lu, Y. (2007), “Culturalizing enterprise software for the Chinese context: an argument for accommodating guanxi-based business practices", International Journal of Production Economics, Vol. 107, pp. 364-379.

Martinsons, M.G. and Westwood, R.I. (1997), "Management IS in the Chinese business culture: an explanatory theory", Information \& Management, Vol. 32, pp. 215-228.

McAfee, A.P. (2006), “Enterprise 2.0: the dawn of emergent collaboration”, MIT Sloan Management Review, Vol. 47 No. 3, pp. $22-28$.

McAfee, A.P. (2009), Enterprise 2.0: New Collaborative Tools for Your Organization's Toughest Challenges, Harvard Business Press, Boston, MA.

Moller, C. (2005), "ERP II: a conceptual framework for next-generation enterprise systems?", Journal of Enterprise Information Management, Vol. 18, pp. 483-497.

Moon, Y.B. and Phatak, D. (2005), “Enhancing ERP system's functionality with discrete event simulation”, Industrial Management \& Data Systems, Vol. 105 No. 9, pp. 1206-1224.

Morand, D.A. (1995), "The role of behavioral formality and informality in the enactment of bureaucratic versus organic organizations", The Academy of Management Review, Vol. 20 No. 4, pp. 831-872.

Mullins, L.J. (2013), Management and Organizational Behaviour, 10th ed., Financial Times, London. Orlikowski, W.J. and Scott, S.V. (2008), "Sociomaterality: challenging the separation of technology", Annals of the Academy of Management, Vol. 2 No. 1, pp. 433-474.

Orlikowski, W.J. (2002), "Knowing in practice: enacting a collective capability in distributed organizing”, Organization Science, Vol. 13 No. 3 , pp. 249-273.

Parthasarthy, R. and Prakash Sethi, S. (1992), "The impact of flexible automation on business strategy and organizational structure", The Academy of Management Review, Vol. 17 No. 1, pp. 86-111.

Peng, G.C. and Nunes, M.B. (2009), "Identification and assessment of risks associated with ERP post-implementation in China", Journal of Enterprise Information Management, Vol. 22 No. 1, pp. 587-614.

Schneckenberg, D. (2009), "Web 2.0 and the shift in corporate governance from control to democracy", Knowledge Management Research \& Practice, Vol. 7 No. 3, pp. 234-248. 
Scott, S.V. and Orlikowski, W.J. (2012), "Reconfiguring relations of accountability: materialization of social media in the travel sector", Accounting, Organizations and Society, Vol. 37, pp. 26-40.

Sia, S.K. and Soh, C. (2007), "An assessment of package - organisation misalignment: institutional and ontological structures", European Journal of Information Systems, Vol. 16, pp. 568-583.

Tsoukas, H. and Vladimirou, E. (2001), “What is organizational knowledge?”, Journal of Management Studies, Vol. 38 No. 7, pp. 973-993.

Woo, H.S. (2007), "Critical success factors for implementing ERP: the case of a Chinese electrics manufacturer", Journal of Manufacturing Technology Management, Vol. 18 No. 4, pp. 431-442.

Yeh, J.Y. and Ouyang, Y.-C. (2010), "How an organization changes in ERP implementation: a Taiwan semiconductor case study", Business Process Management Journal, Vol. 16, pp. 209-225.

Yin, R. (2009), Case Study Research: Design and Methods, 4th ed., Sage Publications, Thousand Oaks, CA.

Zhao, D. and Rosson, B.M. (2009), "How and why people Twitter: the role that micro-blogging plays in informal communication at work", Proceedings of the ACM 2009 international conference on Supporting group work, 2009, ACM, New York, NY, pp. 43-252.

\section{FURTHER READING}

Hong, W.S. (2007), "Critical success factors for implementing ERP: the case of a Chinese electrics manufacturer", Journal of Manufacturing Technology management, Vol. 18 No. 4, pp. 431-442.

Irvine, J.T. (2011), “Formality and informality in communicative events", American Anthropologist, New Series, Vol. 81 No. 4, pp. 773-790.

Lyytinen, K. and Newman, M. (2008), "Explaining information systems change: a punctuated socio-technical change model”, European Journal of Information Systems, Vol. 17 No. 6, pp. 589-613.

\section{Appendix}

Interviewees and

number of

participants

\section{Company A}

IT manager (1)

Operation manager

(1)

\section{Company $B$}

Production manager

(1)

Technical department manager (1)

\section{Company $C$}

Technical department

manager (1)

Operation manager

(1)

HR manager (1)

\section{Company D}

IT manager and

operation (1)

ERP project manager
Company-wide perspectives on the use of an ERP to support daily operations

Operating the ERP and understanding the usage of the system in the entire organisation

Company-wide perspectives on the use of an ERP to support daily operations

Operating the ERP and understand the usage of the system in the entire organisation

Overall business processes and the use of the ERP

Production activities and overall picture of the ERP system in production supports Company-wide perspectives on the organisational context Yes in relation to the use of an ERP and an informal system

No

Yes

No

No

\begin{tabular}{lll}
\multicolumn{3}{c}{ Interview objectives } \\
& The use of & Attitude \\
Company & enterprise & towards \\
background & systems & informality \\
\hline
\end{tabular}

Yes

No

Yes

Yes

$\begin{array}{lll}\text { Yes } & \text { Yes } & \text { Yes } \\ \text { No } & \text { Yes } & \text { No }\end{array}$

Yes

No

Yes

Yes

Yes

Yes

Operating the system and understanding the overall business processes related to the use of the ERP The implementation of an ERP

$\begin{array}{lll}\text { No } & \text { Yes } & \text { No } \\ \text { Yes } & \text { Yes } & \text { Yes }\end{array}$

